\title{
Meta-analysis of the diagnostic performance of circulating microRNAs for pancreatic cancer
}

\section{Cheng Peng}

Central South University Third Xiangya Hospital

Zhiqiang Li

Central South University Third Xiangya Hospital

Lihua Huang

Central South University Third Xiangya Hospital

Wenzhe Gao

Central South University Third Xiangya Hospital

Jiale Wang

Central South University Third Xiangya Hospital

Yunfei Liu

Central South University Third Xiangya Hospital

Xia Li

Central South University Third Xiangya Hospital

Xiao Yu ( $\square$ yuxiaoyx4@126.com)

Central South University Third Xiangya Hospital https://orcid.org/0000-0002-3172-8606

\section{Research article}

Keywords: pancreatic cancer, microRNAs, diagnosis, meta-analysis, circulating

Posted Date: December 6th, 2019

DOI: https://doi.org/10.21203/rs.2.18339/v1

License: (c) (i) This work is licensed under a Creative Commons Attribution 4.0 International License. Read Full License

Version of Record: A version of this preprint was published at International Journal of Medical Sciences on January 1st, 2021. See the published version at https://doi.org/10.7150/ijms.52706. 


\section{Abstract}

Background: Pancreatic cancer (PC) is characterized by high malignancy and poor prognosis. Detection of circulating microRNAs (miRNAs) is one of the liquid biopsy approaches. Numerous researches have suggested that some differentially expressed miRNAs may be promising diagnostic markers for PC, but the results varied among studies. The present study aimed to summarize the diagnostic accuracy of circulating miRNAs, carbohydrate antigen 19-9 (CA19-9), and the combination of miRNAs and CA19-9.

Methods: A literature search of online databases including Pubmed, Embase, Cochrane Library, China National Knowledge Infrastructure (CNKI) and WanFang was conducted. Relative data were extracted from eligible included studies and a meta-analysis was performed.

Results: A total of 46 studies involving 4,326 PC patients and 4,277 non-PC controls were included. The pooled SEN, SPE, and AUC of circulating miRNAs in differentiating PC from non-PC controls were 0.79 (0.77-0.81), 0.77 (0.75-0.79), and 0.85 (0.81-0.87), respectively. For CA19-9, the SEN, SPE, and AUC were $0.78(0.75-0.80), 0.90(0.85-0.94)$ and 0.85 (0.82-0.88), respectively. The combination of miRNAs and CA19-9 greatly improved the SEN, SPE, AUC to 0.84 (0.80-0.87), 0.91 (0.89-0.93) and 0.94 (0.92-0.96), respectively. Circulating miRNAs also yielded an acceptable diagnostic accuracy for early-stage PC with a SEN of 0.79 (0.76-0.82), a SPE of 0.74 (0.68-0.79) and an AUC of 0.81 (0.77-0.84).

Conclusions: Circulating miRNAs exhibited a satisfactory diagnostic performance for PC, even early-stage PC. The combination of circulating miRNAs and the traditional marker CA19-9 can further improve the diagnostic accuracy, providing a novel strategy for PC diagnosis.

\section{Background}

Pancreatic cancer $(\mathrm{PC})$ is a highly malignant digestive malignancy characterized by strong invasiveness, high recurrence rate, and poor prognosis, therefore, it is called "the king of cancer". In 2018, there were approximately 458,918 new cases of pancreatic cancer worldwide, accounting for $2.5 \%$ of all new cases of cancer. Meanwhile, 432,242 patients died of pancreatic cancer, it is the seventh most common cause of cancer-related deaths[1].

According to the recommendation statement of the US Preventive Services Task Force (USPSTF), screening for pancreatic cancer in asymptomatic individuals is currently not recommended[2]. However, early detection is valuable for individuals with high-risk factors (such as familial risk) for pancreatic cancer, which can increase resection rates and achieve longer median survival[3]. Overall, the five-year survival rate for pancreatic cancer is $9.3 \%$, but it is largely determined by the stage at which it is diagnosed. For PC patients with metastatic disease at the time of diagnosis, the five-year survival rate is $2.9 \%$. If the regional disease is present, the 5 -year survival rate is $12.4 \%$. For localized PC patients, the five-year survival rate can increase to $37.4 \%[4]$.

Conventional imaging methods, such as computed tomography (CT), magnetic resonance imaging (MRI), ultrasound (US), as well as serum marker carbohydrate antigen 19 - 9 (CA19-9), has been widely used so far, but the diagnostic accuracy of these modalities may be suboptimal[5], especially for early-stage patients[6]. Endoscopic ultrasonography (EUS) has progressively been considered to be the most accurate diagnostic tool, since it not only has higher sensitivity and specificity but also can obtain suspected tissue specimen for pathological confirmation by EUS-guided fine-needle aspiration (EUS-FNA). However, its invasiveness and risk of sedation make it only suitable for selected individuals[7, 8]. In this clinical setting, liquid biopsy is of great interest from a scientific and clinical perspectives because of its noninvasiveness, higher sensitivity and cost-efficiency[9]. Numerous biomarkers derived from pancreatic cancer, including circulating tumor cells (CTCs), cell-free circulating tumor DNAs (cfDNAs), circulating microRNAs (miRNAs), long non-coding RNAs (LncRNAs), proteins, metabolites, circulating tumor extracellular vesicles (e.g., exosomes) and tumor educated platelets (TEPs) can be detected by Liquid biopsy[6, 9].

MiRNAs are a class of non-coding RNAs of 19-25 nucleotides in length, which regulate protein synthesis at the post-transcriptional level and play an indispensable role in cancer initiation, proliferation, progression, metastasis and chemo-resistance[10]. Since 2010, many researches on the application of circulating miRNAs for the diagnosis of pancreatic cancer have been published. The purpose of the present study is to summarize these original studies and evaluate the diagnostic performance of circulating miRNAs for pancreatic cancer.

\section{Methods}

\subsection{Literature search and study selection}

The process of literature search and study selection was in accordance with the PRISMA guideline[11]. The combination of Mesh terms and entry terms was applied to search the mainstream databases, including Pubmed, Embase, and Cochrane Library. We also searched Chinese databases including China National Knowledge Infrastructure (CNKI) and WanFang database. Besides, we conducted a manual search for the potentially eligible studies which may be omitted according to the review articles' reference lists. The last retrieval date was August 20, 2019. The search terms we used include: (1) circulating, circulatory, serum, plasma, blood; (2) microRNAs, miRNAs, miR, panel; (3) Pancreatic Neoplasms, Pancreatic Intraductal Neoplasms, pancreatic cancer, cancer of pancreas, pancreatic cancer, carcinoma, pancreas, pancreatic 
ductal adenocarcinoma, PDAC; (4) screen, diagnosis, diagnostic, prediction, predict, monitor, detection, detect, predictor, marker, sensitivity, specificity, AUC.

We obtained a substantial number of retrieval records through a database and manual search. First of all, the duplicated publications were removed by the Endnote X9 software, and then we checked again to ensure that there was no duplicate record. The remaining articles were evaluated based on titles and abstracts and were included for full-text assessment if they meet all inclusion criteria: (1) The study population consists of patients with PC and non-PC controls; (2) The marker being studied is circulating miRNAs; (3) The study is diagnostic research. Any article would be excluded in the process of full-text assessment if its data is found to be insufficient.

\subsection{Quality assessment}

The quality assessment of included studies was assessed using the QUADAS-2 (Quality Assessment of Diagnostic Accuracy Studies 2) tool, which has been widely used since its publication in 2011[12]. The QUADAS-2 tool contains four domains including "patient selection", "index test", "reference standard", "flow and timing" and is able to evaluate the risk of bias and concerns about the applicability of the included studies objectively. The process of quality assessment and mapping was finished in Revman 5.3 software.

\subsection{Data extraction and statistical analysis}

The process of data extraction was completed by two researchers independently, one extracted data and another rechecked the data. The original data was filled in a standardized form where the items including: (1) General information of the article: the name of the first author, publication year, country; (2) Research content: specimen type, conference test, the studied miRNAs or other markers and their corresponding expression levels in PC patients, normalization control; (3) Data for meta-analysis: the number of PC patients and non-PC controls, the composition of controls population, diagnostic sensitivity (SEN) and specificity (SPE) or the number of true positive (TP), false positive (FP), true negative (TN), and false negative (FN) in the standard diagnostic test if available.

The extracted original data were regrouped according to different research purposes. Then we performed statistical analysis in STATA 14.0 software to obtain the pooled sensitivity, specificity, positive likelihood ratio (PLR), negative likelihood ratio (NLR), diagnostic odds ratio (DOR) and their corresponding $95 \%$ confidence interval $(\mathrm{Cl})$. We also plotted the summary receiver operating characteristics curve (sROC) to obtain the value of the area under the curve (AUC) and the corresponding $95 \% \mathrm{Cl}$.

An $\mathrm{I}^{2}$ value greater than $50 \%$ was suggestive of substantial heterogeneity in which subgroup analysis according to professional knowledge was performed to identify the source of heterogeneity. The existence of a threshold effect was detected by meta-disc software. Publication bias was assessed using Deeks' funnel plots. A sensitivity analysis was used to confirm the stability of results. A P value $<0.05$ was considered statistically significant.

\section{Results}

\subsection{The characteristics and quality of the included studies}

After duplicate removal, title and abstract assessment and full-text evaluation, we finally included 46 studies involving 4,326 PC patients and 4,277 non-PC controls. The characteristics of included studies were listed in Table 1. Among these original studies, 34 studies were conducted in Asia[13-46], 6 studies in Europe[47-52], 4 studies in North America[53-56], 1 study in Africa[57], and 1 study in South America[58]. The publication year were $2019(n=2), 2018(n=5), 2017(n=4), 2016(n=6), 2015(n=7), 2014(n=11), 2013(n=4), 2012(n=2), 2011(n=4)$, $2009(n=1)$. The flow diagram of literature search and study selection was detailed in Fig. $1(A)$. 
Table 1

Characteristics of included studies

\begin{tabular}{|c|c|c|c|c|c|c|c|c|c|c|}
\hline \multirow[t]{2}{*}{ author } & \multirow[t]{2}{*}{ year } & \multirow[t]{2}{*}{ region } & \multirow[t]{2}{*}{ specimen } & \multirow{2}{*}{$\begin{array}{l}\text { conference } \\
\text { test }\end{array}$} & \multirow{2}{*}{$\begin{array}{l}\text { markers } \\
\text { and } \\
\text { expression } \\
\text { level } \\
\text { in PC } \\
\text { patients }\end{array}$} & \multirow{2}{*}{$\begin{array}{l}\text { normalization } \\
\text { controls }\end{array}$} & \multicolumn{2}{|c|}{ PC patients } & \multicolumn{2}{|c|}{ non-PC controls } \\
\hline & & & & & & & No. & population & No. & population \\
\hline Xuan Zou & 2019 & China & serum & Histopathology & $\begin{array}{l}\text { let-7b-5p } \\
\uparrow \varangle m i R- \\
192-5 p \uparrow \square \\
19 a-3 p \uparrow \square \\
19 b-3 p \uparrow \square \\
223-3 p \uparrow \square \\
25-3 p \uparrow\end{array}$ & cel-miR-34 & 159 & $\mathrm{PC}$ & 137 & $\mathrm{HC}$ \\
\hline $\begin{array}{l}\text { Zebo } \\
\text { Huang }\end{array}$ & 2019 & China & serum & Histopathology & $\operatorname{miR}-16 \uparrow$ & cel-miR-39 & 155 & PC & 137 & $\mathrm{HC}$ \\
\hline $\begin{array}{l}\text { Takuma } \\
\text { Goto }\end{array}$ & 2018 & Japan & serum & Imaging & $\begin{array}{l}\text { miR-191 } \\
\uparrow \varangle 21 \uparrow \rrbracket \\
451 \mathrm{a} \uparrow \square \\
\text { CEA } \uparrow \square \\
\text { CA19-9 } \uparrow\end{array}$ & unclear & 32 & $\mathrm{PC}$ & 22 & $\begin{array}{l}\text { GBP(4) } \square \\
\text { Chronic } \\
\text { gastritis(3)! } \\
\text { Gallbladder } \\
\text { stone(2) }] \\
\text { ADM(2) } \\
\text { Liver } \\
\text { cyst(1) }] \\
\text { IBS(1) }] \\
\text { Accessory } \\
\text { spleen(1) } \\
\text { Only } \\
\text { symptom(7) }\end{array}$ \\
\hline $\begin{array}{l}\text { Francesca } \\
\text { Tavano }\end{array}$ & 2018 & Italy & plasma & $\begin{array}{l}\text { Histopathology } \\
\text { or Imaging }\end{array}$ & $\begin{array}{l}\operatorname{miR}-1290 \\
\uparrow \otimes C A 19-9 \\
\uparrow\end{array}$ & unclear & 167 & PC & 267 & $\mathrm{HC}$ \\
\hline Rei Suzuki & 2018 & Japan & serum & Histopathology & $\begin{array}{l}\text { miR-let-7d } \\
\downarrow \mathbb{D C E A} \uparrow \square \\
\text { CA19-9 } \uparrow\end{array}$ & unclear & 45 & PC & 42 & $\begin{array}{l}\mathrm{CP}(18) \square \\
\text { Biliary } \\
\text { stone(20)! } \\
\text { others(4) }\end{array}$ \\
\hline Jin Wang & 2018 & USA & plasma & Histopathology & $\begin{array}{l}\operatorname{miR}-21 \uparrow \square \\
210 \uparrow \otimes 155 \\
\uparrow \otimes 196 a \uparrow\end{array}$ & miR-16 & 49 & $\mathrm{PC}$ & 36 & $\mathrm{HC}$ \\
\hline Xin Zhou & 2018 & China & plasma & Histopathology & $\begin{array}{l}\text { miR-122- } \\
5 p \uparrow \square \\
125 b-5 p \\
\uparrow \otimes 192-5 p \\
\uparrow \otimes 193 b-3 p \\
\uparrow \nabla 221-3 p \\
\uparrow \otimes 27 b-3 p \\
\uparrow\end{array}$ & miR-103a & 216 & $\mathrm{PC}$ & 220 & $\mathrm{HC}$ \\
\hline $\begin{array}{l}\text { ARZUGUL } \\
\text { Ablet }\end{array}$ & 2018 & China & plasma & Histopathology & $\begin{array}{l}\operatorname{miR}-21 \uparrow \square \\
155 \uparrow\end{array}$ & U6 & 42 & PC & 84 & $\begin{array}{l}\mathrm{CP}(42) \\
\mathrm{HC}(42)\end{array}$ \\
\hline Xianyin Lai & 2017 & China & plasma & Histopathology & $\begin{array}{l}\text { miR-10b } \\
\uparrow \otimes 20 a \uparrow \square \\
21 \uparrow \varangle 30 c \\
\uparrow \otimes 106 b \uparrow \square \\
181 a \uparrow \square \\
\text { let-7a } \downarrow \square \\
122 \uparrow\end{array}$ & miR-425-5p & 29 & $\mathrm{PC}$ & 6 & $\mathrm{HC}$ \\
\hline Kai Qu & 2017 & China & serum & Histopathology & $\underset{\uparrow}{\operatorname{miR}-21-5 p}$ & cel-miR-39 & 56 & PC & 15 & $\mathrm{HC}$ \\
\hline $\begin{array}{l}\text { Yongqiang } \\
\text { Hua }\end{array}$ & 2017 & China & serum & Unclear & miR-373 $\downarrow$ & U6 & 103 & PC & 50 & $\mathrm{HC}$ \\
\hline
\end{tabular}




\begin{tabular}{|c|c|c|c|c|c|c|c|c|c|c|}
\hline \multirow[t]{2}{*}{ author } & \multirow[t]{2}{*}{ year } & \multirow[t]{2}{*}{ region } & \multirow[t]{2}{*}{ specimen } & \multirow{2}{*}{$\begin{array}{l}\text { conference } \\
\text { test }\end{array}$} & \multirow{2}{*}{$\begin{array}{l}\text { markers } \\
\text { and } \\
\text { expression } \\
\text { level } \\
\text { in PC } \\
\text { patients }\end{array}$} & \multirow{2}{*}{$\begin{array}{l}\text { normalization } \\
\text { controls }\end{array}$} & \multicolumn{2}{|c|}{ PC patients } & \multicolumn{2}{|c|}{ non-PC controls } \\
\hline & & & & & & & No. & population & No. & population \\
\hline $\begin{array}{l}\text { Neveen } \\
\text { Abd El } \\
\text { Moneim } \\
\text { Hussein }\end{array}$ & 2017 & Egypt & plasma & Histopathology & $\begin{array}{l}\text { miR-22-3p } \\
\uparrow \otimes 643 b-3 p \\
\uparrow \otimes 885-5 p \\
\uparrow \otimes C A 19-9 \\
\uparrow\end{array}$ & miR-3196 & 35 & PC & 15 & $\mathrm{HC}$ \\
\hline Ting Deng & 2016 & China & serum & Histopathology & $\operatorname{miR}-25 \uparrow$ & unclear & 303 & PC & 760 & 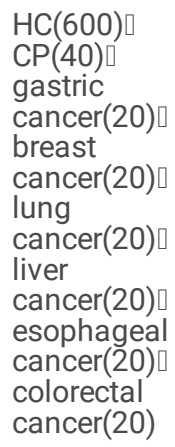 \\
\hline $\begin{array}{l}\text { Bárbara } \\
\text { Alemar }\end{array}$ & 2016 & Brazil & serum & Histopathology & $\begin{array}{l}\operatorname{miR}-21 \uparrow \square \\
34 \mathrm{a} \uparrow\end{array}$ & cel-miR-39 & 24 & PC & 9 & $\mathrm{HC}$ \\
\hline Zhe Cao & 2016 & China & plasma & Histopathology & 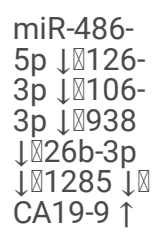 & U6 & 185 & $\mathrm{PC}$ & 158 & $\begin{array}{l}\text { CP(73)! } \\
\text { OPN(85) }\end{array}$ \\
\hline $\begin{array}{l}\text { Pavel } \\
\text { Skrha }\end{array}$ & 2016 & $\begin{array}{l}\text { Czech } \\
\text { Republic }\end{array}$ & serum & Histopathology & $\begin{array}{l}\operatorname{miR} 196 \uparrow \square \\
200 \uparrow \rrbracket \\
\text { CA19-9 } \uparrow\end{array}$ & miR-191】454 & 77 & PC & 64 & $\mathrm{HC}$ \\
\hline $\begin{array}{l}\text { Manabu } \\
\text { Akamatsu }\end{array}$ & 2016 & Japan & serum & Histopathology & $\begin{array}{l}\text { miR-7 } \uparrow \square \\
34 a \uparrow \square \\
181 d \uparrow \square \\
193 b \uparrow\end{array}$ & cel-miR-39 & 69 & PC & 15 & AIP \\
\hline $\begin{array}{l}\text { Julia S. } \\
\text { Johansen }\end{array}$ & 2016 & Denmark & serum & Histopathology & 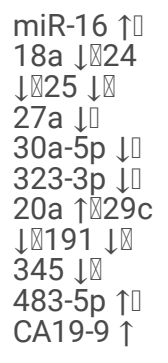 & unclear & 417 & PC & 340 & $\begin{array}{l}\text { PAC(33)! } \\
\text { CP(59)! } \\
\text { HC(248) }\end{array}$ \\
\hline $\begin{array}{l}\text { Bindhu } \\
\text { Madhavan }\end{array}$ & 2015 & Germany & serum & Histopathology & $\begin{array}{l}\operatorname{miR}-1246 \\
\uparrow \varangle 4644 \uparrow \rrbracket \\
3976 \uparrow \rrbracket \\
4306 \uparrow\end{array}$ & $\begin{array}{l}\text { U430U6ه18S } \\
\text { and 5S rRNA }\end{array}$ & 87 & PC & 51 & $\begin{array}{l}\mathrm{CP}(17) \square \\
\mathrm{BPT}(14) \square \\
\mathrm{HC}(20)\end{array}$ \\
\hline $\begin{array}{l}\text { Shuhei } \\
\text { Komatsu }\end{array}$ & 2015 & Japan & plasma & Histopathology & $\operatorname{miR}-223 \uparrow$ & cel-miR-39 & 71 & PC & 67 & $\mathrm{HC}$ \\
\hline $\begin{array}{l}\text { Mahito } \\
\text { Miyamae }\end{array}$ & 2015 & Japan & plasma & Histopathology & miR-744 $\uparrow$ & cel-miR-39 & 94 & PC & 68 & $\mathrm{HC}$ \\
\hline Hu Yingxia & 2015 & China & plasma & Histopathology & $\begin{array}{l}\operatorname{miR}-196 a \\
\uparrow \otimes 210 \uparrow \rrbracket \\
\text { CA19-9 } \uparrow\end{array}$ & U6 & 60 & PC & 30 & $\begin{array}{l}\mathrm{CP}(20) \square \\
\mathrm{HC}(10)\end{array}$ \\
\hline
\end{tabular}




\begin{tabular}{|c|c|c|c|c|c|c|c|c|c|c|}
\hline \multirow[t]{2}{*}{ author } & \multirow[t]{2}{*}{ year } & \multirow[t]{2}{*}{ region } & \multirow[t]{2}{*}{ specimen } & \multirow{2}{*}{$\begin{array}{l}\text { conference } \\
\text { test }\end{array}$} & \multirow{2}{*}{$\begin{array}{l}\text { markers } \\
\text { and } \\
\text { expression } \\
\text { level } \\
\text { in PC } \\
\text { patients }\end{array}$} & \multirow{2}{*}{$\begin{array}{l}\text { normalization } \\
\text { controls }\end{array}$} & \multicolumn{2}{|c|}{ PC patients } & \multicolumn{2}{|c|}{ non-PC controls } \\
\hline & & & & & & & No. & population & No. & population \\
\hline Hu Yingxia & 2015 & China & plasma & Histopathology & $\begin{array}{l}\text { miR-210 } \\
\uparrow \nabla C A 19-9 \\
\uparrow \nabla C A 242 \\
\uparrow \triangle \mathrm{CEA} \uparrow\end{array}$ & U6 & 60 & PC & 30 & $\begin{array}{l}\mathrm{CP}(20) \square \\
\mathrm{HC}(10)\end{array}$ \\
\hline $\begin{array}{l}\text { Wang } \\
\text { Xiaogang }\end{array}$ & 2015 & China & serum & $\begin{array}{l}\text { Histopathology } \\
\text { or Imaging }\end{array}$ & $\begin{array}{l}\text { miR-155 } \\
\uparrow \otimes C A 19-9 \\
\uparrow\end{array}$ & cel-miR-39 & 110 & PC & 70 & $\mathrm{CP}$ \\
\hline $\begin{array}{l}\text { Wang } \\
\text { Shanbing }\end{array}$ & 2015 & China & plasma & $\begin{array}{l}\text { Histopathology } \\
\text { or Imaging }\end{array}$ & $\begin{array}{l}\operatorname{miR}-21 \uparrow \square \\
483-3 p \uparrow \uparrow \\
155 \uparrow \rrbracket \\
\text { CA19-9 } \uparrow\end{array}$ & miR-16 & 43 & PC & 21 & $\mathrm{HC}$ \\
\hline Ling Gao & 2014 & China & plasma & Histopathology & $\begin{array}{l}\text { CA19-9 } \uparrow \square \\
\text { miR-16 } \uparrow\end{array}$ & cel-miR-39 & 70 & PC & 120 & $\begin{array}{l}\mathrm{HC}(50) \square \\
\mathrm{CP}(70)\end{array}$ \\
\hline $\begin{array}{l}\text { Gregory A. } \\
\text { Cote }\end{array}$ & 2014 & USA & plasma & Histopathology & $\begin{array}{l}\operatorname{miR}-10 b \\
\uparrow \varangle 30 c \uparrow \square \\
106 \mathrm{~b} \uparrow \square \\
155 \uparrow \varangle 212 \\
\uparrow\end{array}$ & miR-425-5p & 40 & PC & 54 & $\begin{array}{l}\mathrm{CP}(30) \square \\
\operatorname{BBD}(24)\end{array}$ \\
\hline $\begin{array}{l}\text { Maosong } \\
\text { Lin }\end{array}$ & 2014 & China & serum & Histopathology & 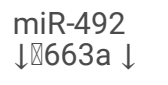 & cel-miR-39 & 49 & PC & 27 & $\mathrm{HC}$ \\
\hline $\begin{array}{l}\text { Qiulan } \\
\text { Chen }\end{array}$ & 2014 & China & plasma & Histopathology & $\begin{array}{l}\text { miR-182 } \\
\uparrow \mathbb{\uparrow} \text { CA19-9 } \\
\uparrow\end{array}$ & U6 & 109 & PC & 38 & $\mathrm{CP}$ \\
\hline Ang Li & 2014 & USA & serum & Histopathology & 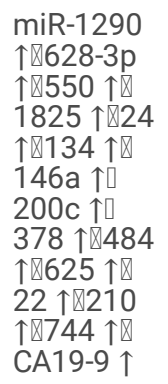 & miR-16 & 41 & PC & 72 & $\begin{array}{l}\mathrm{HC}(19) \square \\
\mathrm{CP}(35) \square \\
\operatorname{pNET}(18)\end{array}$ \\
\hline $\begin{array}{l}\text { Nicolai A. } \\
\text { Schultz }\end{array}$ & 2014 & Denmark & serum & Histopathology & 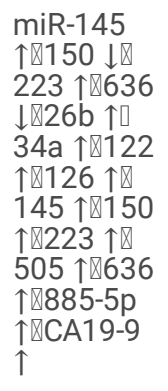 & ath-miR-159a & 409 & PC & 347 & $\begin{array}{l}\mathrm{HC}(322) \square \\
\mathrm{CP}(25)\end{array}$ \\
\hline $\begin{array}{l}\text { Emily P. } \\
\text { Slater }\end{array}$ & 2014 & Germany & serum & Histopathology & $\begin{array}{l}\operatorname{miR}-196 a \\
\uparrow \otimes 196 b \uparrow\end{array}$ & miR-24 & 24 & PC & 20 & $\begin{array}{l}\mathrm{CP}(10) \square \\
\mathrm{HC}(10)\end{array}$ \\
\hline $\begin{array}{l}\text { Ganepola } \\
\text { AP } \\
\text { Ganepola }\end{array}$ & 2014 & USA & plasma & Histopathology & $\begin{array}{l}\text { miR-885- } \\
5 p \uparrow \uparrow 22- \\
3 p \uparrow \square \\
642 b-3 p \\
\uparrow \otimes C A 19-9 \\
\uparrow\end{array}$ & miR-3196 & 11 & PC & 22 & $\mathrm{HC}$ \\
\hline $\begin{array}{l}\text { Jing } \\
\text { Zhang }\end{array}$ & 2014 & China & serum & Histopathology & $\begin{array}{l}\operatorname{miR}-192 \\
\uparrow \varangle 194 \uparrow\end{array}$ & U6 & 70 & PC & 40 & $\mathrm{HC}$ \\
\hline
\end{tabular}




\begin{tabular}{|c|c|c|c|c|c|c|c|c|c|c|}
\hline \multirow[t]{2}{*}{ author } & \multirow[t]{2}{*}{ year } & \multirow[t]{2}{*}{ region } & \multirow[t]{2}{*}{ specimen } & \multirow{2}{*}{$\begin{array}{l}\text { conference } \\
\text { test }\end{array}$} & \multirow{2}{*}{$\begin{array}{l}\text { markers } \\
\text { and } \\
\text { expression } \\
\text { level } \\
\text { in PC } \\
\text { patients }\end{array}$} & \multirow{2}{*}{$\begin{array}{l}\text { normalization } \\
\text { controls }\end{array}$} & \multicolumn{2}{|c|}{ PC patients } & \multicolumn{2}{|c|}{ non-PC controls } \\
\hline & & & & & & & No. & population & No. & population \\
\hline $\begin{array}{l}\text { Wenzheng } \\
\text { Pan }\end{array}$ & 2014 & China & plasma & Histopathology & $\begin{array}{l}\operatorname{miR}-210 \\
\uparrow \otimes 25 \uparrow \otimes \\
\text { CA19-9 } \uparrow\end{array}$ & cel-miR-39 & 30 & PC & 26 & $\mathrm{HC}$ \\
\hline Wei Shi & 2014 & China & plasma & $\begin{array}{l}\text { Histopathology } \\
\text { or Imaging }\end{array}$ & $\begin{array}{l}\operatorname{miR}-155 \\
\uparrow \otimes 196 a \uparrow \square \\
\text { CA19-9 } \uparrow \square \\
\text { CA242 } \uparrow \square \\
\text { CEA } \uparrow\end{array}$ & U6 & 60 & PC & 30 & $\begin{array}{l}\mathrm{CP}(20) \square \\
\mathrm{HC}(10)\end{array}$ \\
\hline $\begin{array}{l}\text { Risheng } \\
\text { Que }\end{array}$ & 2013 & China & serum & Histopathology & $\begin{array}{l}\operatorname{miR}-17-5 p \\
\uparrow \otimes 21 \uparrow\end{array}$ & U6 & 22 & $\mathrm{PC}$ & 27 & $\begin{array}{l}\mathrm{AC}(6) \square \\
\mathrm{BPN}(7) \square \\
\mathrm{CP}(6) \square \mathrm{HC}(8)\end{array}$ \\
\hline $\begin{array}{l}\text { T } \\
\text { Kawaguchi }\end{array}$ & 2013 & Japan & plasma & Histopathology & $\operatorname{miR}-221 \uparrow$ & U6 & 47 & PC & 9 & BPN \\
\hline $\begin{array}{l}\text { Wansheng } \\
\text { Wang }\end{array}$ & 2013 & China & serum & Unclear & $\begin{array}{l}\operatorname{miR}-27 a- \\
3 p \uparrow \square \\
\text { CA19-9 }\end{array}$ & U6 & 129 & PC & 163 & $\begin{array}{l}\mathrm{BPD}(103) \square \\
\mathrm{HC}(60)\end{array}$ \\
\hline $\begin{array}{l}\text { Chenyan } \\
\text { Zhao }\end{array}$ & 2013 & China & serum & Histopathology & $\operatorname{miR}-192 \uparrow$ & U6 & 80 & PC & 40 & $\mathrm{HC}$ \\
\hline Rui Liu & 2012 & China & serum & Histopathology & 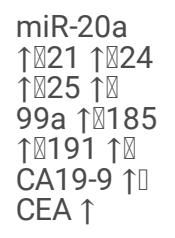 & $\begin{array}{l}\text { serum } \\
\text { volume }\end{array}$ & 123 & PC & 61 & $\begin{array}{l}\mathrm{HC}(52) \square \\
\mathrm{CP}(9)\end{array}$ \\
\hline Feng Pan & 2012 & China & plasma & Histopathology & $\begin{array}{l}\operatorname{miR}-451 \\
\uparrow \underset{\uparrow}{\uparrow}\end{array}$ & cel-miR-39 & 24 & PC & 24 & $\mathrm{HC}$ \\
\hline $\begin{array}{l}\text { Jianqiang } \\
\text { Liu }\end{array}$ & 2011 & China & plasma & $\begin{array}{l}\text { Histopathology } \\
\text { or Imaging }\end{array}$ & $\begin{array}{l}\operatorname{miR}-16 \uparrow \square \\
196 a \uparrow \square \\
\text { CA19-9 } \uparrow\end{array}$ & cel-miR-39 & 138 & $\mathrm{PC}$ & 175 & $\begin{array}{l}\mathrm{HC}(68) \square \\
\mathrm{CP}(107)\end{array}$ \\
\hline $\begin{array}{l}\text { Jianqiang } \\
\text { Liu }\end{array}$ & 2011 & China & plasma & Histopathology & $\begin{array}{l}\operatorname{miR}-181 a \\
\uparrow \otimes 181 b \uparrow \uparrow \\
210 \uparrow Q \\
\text { CA19-9 } \uparrow\end{array}$ & cel-miR-39 & 55 & PC & 96 & $\begin{array}{l}\mathrm{HC}(39) \square \\
\mathrm{CP}(57)\end{array}$ \\
\hline $\begin{array}{l}\text { Jianqiang } \\
\text { Liu }\end{array}$ & 2011 & China & plasma & Histopathology & $\operatorname{miR}-21 \uparrow$ & cel-miR-39 & 45 & $\mathrm{PC}$ & 75 & $\begin{array}{l}\mathrm{HC}(30) \square \\
\mathrm{CP}(45)\end{array}$ \\
\hline $\begin{array}{l}\text { Jianqiang } \\
\text { Liu }\end{array}$ & 2011 & China & plasma & Histopathology & miR-155 $\uparrow$ & cel-miR-39 & 62 & PC & 97 & $\begin{array}{l}\mathrm{HC}(36) \square \\
\mathrm{CP}(61)\end{array}$ \\
\hline
\end{tabular}

We found that there was a high risk of bias in the domain of "Patient Selection" after the process of quality assessment using the QUADAS-2 tool. According to the statement of the QUADAS-2 group, an ideal diagnostic study should enroll a proportion of suspected patients ("difficult-todiagnose patients") to reduce the risk of bias[12]. But all the included studies included patients with a definitive diagnosis, which resulted in a high risk of bias in this domain. Besides, there is a large proportion of the unclear risk of bias in the domain of "Index Test", because the researchers of these included studies did not describe how they determined the threshold. The risk of bias was low in the domain of "Reference test" and "Flow and Timing". All domains exhibited low concerns of applicability. The results of the quality assessment were shown in Fig. 1 (BC).

\subsection{The diagnostic performance of circulating miRNAs}

Circulating single miRNAs, which means that only one miRNA was used for diagnosis, distinguished PC patients from non-PC controls with a SEN of 0.78 (0.76-0.81), a SPE of 0.78 (0.75-0.80), and the PLR, NLR, DOR AUC were 3.55 (3.13-4.02), 0.28 (0.25-0.31), 12.78 (10.19-16.03) and 0.85 (0.82-0.88), respectively. The circulating miRNAs panel, which means multiple miRNAs were applied for diagnosis, discriminated cases with PC from case of non-PC with a SEN of 0.79 (0.76-0.82), a SPE of $0.75(0.72-0.78)$, a PLR of $3.16(2.74-3.65)$, a NLR of 0.28 (0.23- 
0.33), a DOR of 11.40 (8.55-15.20), and an AUC of $0.84(0.80-0.87)$. There is no significant difference in the diagnostic efficacy between single miRNAs and miRNAs panels. Overall, the SEN, SPE, PLR, NLR, DOR, AUC of circulating miRNAs (including single miRNAs and miRNAs panel) in differentiating patients with PC from non-PC controls were $0.79(0.77-0.81), 0.77(0.75-0.79), 3.38(3.08-3.72), 0.28(0.25-0.31), 12.22$ (10.23-14.60) and $0.85(0.81-0.87)$, respectively. The results were shown in Table 2 and Fig. 2 (A-C). 
Table 2

The results of meta-analysis

\begin{tabular}{|c|c|c|c|c|c|c|c|c|c|}
\hline & SEN(95\%Cl) & SPE(95\%Cl) & PLR(95\%Cl) & $\operatorname{NLR}(95 \% \mathrm{Cl})$ & $\operatorname{DOR}(95 \% \mathrm{Cl})$ & $\operatorname{AUC}(95 \% \mathrm{Cl})$ & $\begin{array}{l}\text { number } \\
\text { of data } \\
\text { sets }\end{array}$ & $\begin{array}{l}\text { number } \\
\text { of PC }\end{array}$ & $\begin{array}{l}\text { number } \\
\text { of } \\
\text { control }\end{array}$ \\
\hline \multicolumn{10}{|l|}{1 miRNAs } \\
\hline $\begin{array}{l}\text { PC vs } \\
\text { non-PC }\end{array}$ & $\begin{array}{l}0.79(0.77- \\
0.81)\end{array}$ & $\begin{array}{l}0.77(0.75- \\
0.79)\end{array}$ & $\begin{array}{l}3.38(3.08- \\
3.72)\end{array}$ & $\begin{array}{l}0.28(0.25- \\
0.31)\end{array}$ & $\begin{array}{l}12.22(10.23- \\
14.60)\end{array}$ & $\begin{array}{l}0.85(0.81- \\
0.87)\end{array}$ & 228 & 13554 & 14474 \\
\hline $\mathrm{PC}$ vs $\mathrm{CP}$ & $\begin{array}{l}0.77(0.74- \\
0.80)\end{array}$ & $\begin{array}{l}0.67(0.62- \\
0.71)\end{array}$ & $\begin{array}{l}2.32(2.01- \\
2.69)\end{array}$ & $\begin{array}{l}0.35(0.30- \\
0.40)\end{array}$ & $\begin{array}{l}6.72(5.10- \\
8.86)\end{array}$ & $\begin{array}{l}0.79(0.75- \\
0.82)\end{array}$ & 48 & 2554 & 1435 \\
\hline PC vs HC & $\begin{array}{l}0.83(0.80- \\
0.85)\end{array}$ & $\begin{array}{l}0.81(0.78- \\
0.83)\end{array}$ & $\begin{array}{l}4.29(3.67- \\
5.02)\end{array}$ & $\begin{array}{l}0.22(0.18- \\
0.26)\end{array}$ & $\begin{array}{l}19.94(14.73- \\
26.98)\end{array}$ & $\begin{array}{l}0.88(0.85- \\
0.91)\end{array}$ & 102 & 5828 & 5983 \\
\hline \multicolumn{10}{|l|}{$\begin{array}{l}1.1 \text { single } \\
\text { miRNAs }\end{array}$} \\
\hline $\begin{array}{l}\text { PC vs } \\
\text { non-PC }\end{array}$ & $\begin{array}{l}0.78(0.76- \\
0.81)\end{array}$ & $\begin{array}{l}0.78(0.75- \\
0.80)\end{array}$ & $\begin{array}{l}3.55(3.13- \\
4.02)\end{array}$ & $\begin{array}{l}0.28(0.25- \\
0.31)\end{array}$ & $\begin{array}{l}12.78(10.19- \\
16.03)\end{array}$ & $\begin{array}{l}0.85(0.82- \\
0.88)\end{array}$ & 148 & 7107 & 6426 \\
\hline $\mathrm{PC}$ vs $\mathrm{CP}$ & $\begin{array}{l}0.73(0.68- \\
0.78)\end{array}$ & $\begin{array}{l}0.68(0.63- \\
0.73)\end{array}$ & $\begin{array}{l}2.28(1.94- \\
2.69)\end{array}$ & $\begin{array}{l}0.39(0.32- \\
0.48)\end{array}$ & $\begin{array}{l}5.80(4.18- \\
8.03)\end{array}$ & $\begin{array}{l}0.76(0.82- \\
0.80)\end{array}$ & 26 & 1081 & 824 \\
\hline PC vs HC & $\begin{array}{l}0.81(0.77- \\
0.85)\end{array}$ & $\begin{array}{l}0.81(0.77- \\
0.84)\end{array}$ & $\begin{array}{l}4.21(3.46- \\
5.12)\end{array}$ & $\begin{array}{l}0.23(0.19- \\
0.29)\end{array}$ & $\begin{array}{l}17.98(12.38- \\
26.10)\end{array}$ & $\begin{array}{l}0.88(0.85- \\
0.90)\end{array}$ & 72 & 3756 & 2686 \\
\hline \multicolumn{10}{|l|}{$\begin{array}{l}1.2 \\
\text { miRNAs } \\
\text { panel }\end{array}$} \\
\hline $\begin{array}{l}\text { PC vs } \\
\text { non-PC }\end{array}$ & $\begin{array}{l}0.79(0.76- \\
0.82)\end{array}$ & $\begin{array}{l}0.75(0.72- \\
0.78)\end{array}$ & $\begin{array}{l}3.16(2.74- \\
3.65)\end{array}$ & $\begin{array}{l}0.28(0.23- \\
0.33)\end{array}$ & $\begin{array}{l}11.40(8.55- \\
15.20)\end{array}$ & $\begin{array}{l}0.84(0.80- \\
0.87)\end{array}$ & 80 & 6447 & 8048 \\
\hline $\mathrm{PC}$ vs $\mathrm{CP}$ & $\begin{array}{l}0.80(0.77- \\
0.83)\end{array}$ & $\begin{array}{l}0.65(0.56- \\
0.73)\end{array}$ & $\begin{array}{l}2.30(1.79- \\
2.95)\end{array}$ & $\begin{array}{l}0.30(0.25- \\
0.37)\end{array}$ & $\begin{array}{l}7.58(4.91- \\
11.70)\end{array}$ & $\begin{array}{l}0.82(0.78- \\
0.85)\end{array}$ & 22 & 1473 & 611 \\
\hline $\mathrm{PC}$ vs HC & $\begin{array}{l}0.86(0.83- \\
0.88)\end{array}$ & $\begin{array}{l}0.81(0.76- \\
0.85)\end{array}$ & $\begin{array}{l}4.47(3.43- \\
5.81)\end{array}$ & $\begin{array}{l}0.18(0.14- \\
0.22)\end{array}$ & $\begin{array}{l}25.43(16.02- \\
40.37)\end{array}$ & $\begin{array}{l}0.90(0.88- \\
0.93)\end{array}$ & 30 & 2072 & 3297 \\
\hline \multicolumn{10}{|c|}{$\begin{array}{l}2 \text { miRNAs combine } \\
\text { CA19-9 }\end{array}$} \\
\hline $\begin{array}{l}P C \text { vs } \\
\text { non-PC }\end{array}$ & $\begin{array}{l}0.84(0.80- \\
0.87)\end{array}$ & $\begin{array}{l}0.91(0.89- \\
0.93)\end{array}$ & $\begin{array}{l}9.77(7.65- \\
12.47)\end{array}$ & $\begin{array}{l}0.17(0.14- \\
0.22)\end{array}$ & $\begin{array}{l}56.01(37.70- \\
83.20)\end{array}$ & $\begin{array}{l}0.94(0.92- \\
0.96)\end{array}$ & 65 & 6121 & 8124 \\
\hline $\mathrm{PC}$ vs $\mathrm{CP}$ & $\begin{array}{l}0.82(0.76- \\
0.87)\end{array}$ & $\begin{array}{l}0.82(0.73- \\
0.89)\end{array}$ & $\begin{array}{l}4.61(2.87- \\
7.40)\end{array}$ & $\begin{array}{l}0.22(0.15- \\
0.32)\end{array}$ & $\begin{array}{l}21.12(9.59- \\
46.51)\end{array}$ & $\begin{array}{l}0.89(0.86- \\
0.91)\end{array}$ & 16 & 1280 & 562 \\
\hline PC vs HC & $\begin{array}{l}0.86(0.81- \\
0.91)\end{array}$ & $\begin{array}{l}0.96(0.94- \\
0.97)\end{array}$ & $\begin{array}{l}19.52(14.92- \\
25.53)\end{array}$ & $\begin{array}{l}0.14(0.10- \\
0.20)\end{array}$ & $\begin{array}{l}136.75(91.16- \\
205.15)\end{array}$ & $\begin{array}{l}0.97(0.96- \\
0.98)\end{array}$ & 20 & 1725 & 3106 \\
\hline \multicolumn{10}{|c|}{$\begin{array}{l}2.1 \text { single miRNAs } \\
\text { combine CA19-9 }\end{array}$} \\
\hline $\begin{array}{l}P C \text { vs } \\
\text { non-PC }\end{array}$ & $\begin{array}{l}0.88(0.85- \\
0.91)\end{array}$ & $\begin{array}{l}0.92(0.88- \\
0.95)\end{array}$ & $\begin{array}{l}10.80(7.12- \\
16.38)\end{array}$ & $\begin{array}{l}0.13(0.10- \\
0.17)\end{array}$ & $\begin{array}{l}84.16(47.15- \\
150.25)\end{array}$ & $\begin{array}{l}0.95(0.92- \\
0.96)\end{array}$ & 12 & 965 & 830 \\
\hline $\mathrm{PC}$ vs $\mathrm{CP}$ & $\begin{array}{l}0.83(0.79- \\
0.87)\end{array}$ & $\begin{array}{l}0.88(0.83- \\
0.92)\end{array}$ & $\begin{array}{l}7.18(4.87- \\
10.58)\end{array}$ & $\begin{array}{l}0.19(0.14- \\
0.24)\end{array}$ & $\begin{array}{l}38.29(22.55- \\
65.00)\end{array}$ & $\begin{array}{l}0.92(0.90- \\
0.94)\end{array}$ & 4 & 349 & 198 \\
\hline $\mathrm{PC}$ vs HC & $\begin{array}{l}0.92(0.87- \\
0.96)\end{array}$ & $\begin{array}{l}0.94(0.87- \\
0.97)\end{array}$ & $\begin{array}{l}15.30(6.88- \\
34.01)\end{array}$ & $\begin{array}{l}0.08(0.05- \\
0.14)\end{array}$ & $\begin{array}{l}189.00(89.48- \\
399.17)\end{array}$ & $\begin{array}{l}0.97(0.95- \\
0.98)\end{array}$ & 5 & 357 & 379 \\
\hline \multicolumn{10}{|c|}{$\begin{array}{l}2.2 \text { miRNAs panel } \\
\text { combine CA19-9 }\end{array}$} \\
\hline $\begin{array}{l}\text { PC vs } \\
\text { non-PC }\end{array}$ & $\begin{array}{l}0.83(0.78- \\
0.86)\end{array}$ & $\begin{array}{l}0.91(0.89- \\
0.93)\end{array}$ & $\begin{array}{l}9.49(7.14- \\
12.61)\end{array}$ & $\begin{array}{l}0.19(0.15- \\
0.25)\end{array}$ & $\begin{array}{l}49.60(31.15- \\
78.98)\end{array}$ & $\begin{array}{l}0.94(0.92- \\
0.96)\end{array}$ & 53 & 5156 & 7294 \\
\hline PC vs CP & $\begin{array}{l}0.81(0.70- \\
0.88)\end{array}$ & $\begin{array}{l}0.79(0.66- \\
0.88)\end{array}$ & $\begin{array}{l}3.88(2.12- \\
7.08)\end{array}$ & $\begin{array}{l}0.24(0.14- \\
0.42)\end{array}$ & $\begin{array}{l}16.04(5.41- \\
47.54)\end{array}$ & $\begin{array}{l}0.87(0.84- \\
0.90)\end{array}$ & 12 & 931 & 364 \\
\hline PC vs HC & $\begin{array}{l}0.83(0.75- \\
0.89)\end{array}$ & $\begin{array}{l}0.96(0.94- \\
0.97)\end{array}$ & $\begin{array}{l}20.40(15.17- \\
27.45)\end{array}$ & $\begin{array}{l}0.17(0.12- \\
0.26)\end{array}$ & $\begin{array}{l}\text { 116.62(71.44- } \\
190.38)\end{array}$ & $\begin{array}{l}0.97(0.95- \\
0.98)\end{array}$ & 15 & 1368 & 2727 \\
\hline
\end{tabular}




\begin{tabular}{|c|c|c|c|c|c|c|c|c|c|}
\hline & SEN( $95 \% \mathrm{Cl})$ & SPE( $(95 \% \mathrm{Cl})$ & PLR(95\%Cl) & $\operatorname{NLR}(95 \% \mathrm{Cl})$ & $\operatorname{DOR}(95 \% \mathrm{Cl})$ & AUC(95\%Cl) & $\begin{array}{l}\text { number } \\
\text { of data } \\
\text { sets }\end{array}$ & $\begin{array}{l}\text { number } \\
\text { of } \mathrm{PC}\end{array}$ & $\begin{array}{l}\text { number } \\
\text { of } \\
\text { control }\end{array}$ \\
\hline \multicolumn{10}{|c|}{$\begin{array}{l}3 \text { Conventional } \\
\text { biomarker ( } P C \text { vs non-PC } \\
\text { ) }\end{array}$} \\
\hline CA19-9 & $\begin{array}{l}0.78(0.75- \\
0.80)\end{array}$ & $\begin{array}{l}0.90(0.85- \\
0.94)\end{array}$ & $\begin{array}{l}7.90(5.14- \\
12.13)\end{array}$ & $\begin{array}{l}0.25(0.22- \\
0.28)\end{array}$ & $\begin{array}{l}31.89(18.96- \\
53.62)\end{array}$ & $\begin{array}{l}0.85(0.82- \\
0.88)\end{array}$ & 51 & 3787 & 4508 \\
\hline CEA & $\begin{array}{l}0.79(0.39- \\
0.96)\end{array}$ & $\begin{array}{l}0.32(0.08- \\
0.72)\end{array}$ & $\begin{array}{l}1.17(0.82- \\
1.65)\end{array}$ & $\begin{array}{l}0.65(0.26- \\
1.60)\end{array}$ & $\begin{array}{l}1.80(0.55- \\
5.88)\end{array}$ & $\begin{array}{l}0.59(0.54- \\
0.63)\end{array}$ & 10 & 500 & 237 \\
\hline CA242 & $\begin{array}{l}0.79(0.52- \\
0.93)\end{array}$ & $\begin{array}{l}0.46(0.21- \\
0.74)\end{array}$ & $\begin{array}{l}1.47(0.95- \\
2.27)\end{array}$ & $\begin{array}{l}0.45(0.21- \\
0.97)\end{array}$ & $\begin{array}{l}3.25(1.14- \\
9.32)\end{array}$ & $\begin{array}{l}0.68(0.63- \\
0.71)\end{array}$ & 5 & 300 & 90 \\
\hline $\begin{array}{l}\text { CA19-9! } \\
\text { CEA! } \\
\text { CA242 }\end{array}$ & $\begin{array}{l}0.77(0.61- \\
0.88)\end{array}$ & $\begin{array}{l}0.66(0.42- \\
0.85)\end{array}$ & $\begin{array}{l}2.29(1.15- \\
4.58)\end{array}$ & $\begin{array}{l}0.35(0.18- \\
0.67)\end{array}$ & $\begin{array}{l}6.61(1.92- \\
22.77)\end{array}$ & $\begin{array}{l}0.79(0.75- \\
0.82)\end{array}$ & 5 & 300 & 90 \\
\hline
\end{tabular}

In addition, we also summarized the SEN, SPE, PLR, NLR, DOR, and AUC of miRNAs in distinguishing PC patients from healthy control (HC) or patients with chronic pancreatitis (CP). The data was listed in Table 2. In general, the diagnostic accuracy of miRNAs in discriminating PC from $\mathrm{HC}$ was higher than that of discriminating PC from CP.

A total of 58 different single miRNAs and 23 miRNAs panels were involved in the 46 inclusion studies. For the single miRNAs and miRNAs panels being studied in one data set, we extracted the diagnostic SEN, SPE, PLR, NLR, and DOR from the original literature. For those being studied in more than 2 data sets, we performed a meta-analysis and obtained pooled diagnostic SEN, SPE, PLR, NLR, DOR. The results were listed in Table S1 and Table S2. Among these single miRNAs, miR-122, 212, 22-3p, 483-3p, 642b-3p, 885-5p yield a high SEN of more than 90\%, while the SPE of miR-25, 223, 17-5p, 223-3p, 30c and 409-3p were greater than 90\%. The SEN and SPE of miR-451, 106b, 10b, 181a, 196b, 20a, let-7a were both greater than $90 \%$. For miRNAs panels, the SEN of the combination of let-7b-5p, miR-192-5p, 19a-3p, 19b-3p, 223-3p, 25-3p exceeded $90 \%$ while the SPE of the combination of miR-1246, 4464, 3976, 4306 was over $90 \%$. The combination of miR-196a, 196b, the combination of miR-451, 409-3p, as well as the combination of 885-5p, 22-3p, 642b-3p exhibited high diagnostic accuracy, with a SEN and SPE both greater than $90 \%$.

\subsection{Circulating miRNAs for the diagnosis of early-stage PC}

Early-stage PC was defined as PC patient with a TNM stage of 0-lla. For this group of patients, the SEN, SPE, PLR, NLR, DOR and AUC of circulating miRNAs were 0.79 (0.76-0.82), 0.74 (0.68-0.79), 2.60 (2.19-3.10), 0.35 (0.30-0.41), 8.14 (5.85-11.33) and 0.81 (0.77-0.84), respectively. MiR-196b and the combination of miR-196a and 196b exhibited high diagnostic accuracy with a SEN and SPE both greater than 90\%. The results were listed in Fig. 2 (D) and Table 3. 
Table 3

The diagnostic performance of circulating miRNAs for early-stage PC

\begin{tabular}{|c|c|c|c|c|c|c|c|c|c|}
\hline miRNAs & $\begin{array}{l}\text { TNM } \\
\text { stage }\end{array}$ & $\begin{array}{l}\text { number } \\
\text { of data } \\
\text { sets }\end{array}$ & $\begin{array}{l}\text { number } \\
\text { of PC }\end{array}$ & $\begin{array}{l}\text { number } \\
\text { of non- } \\
\text { PC }\end{array}$ & SEN $(95 \% \mathrm{Cl})$ & SPE $(95 \% \mathrm{Cl})$ & $\operatorname{PLR}(95 \% \mathrm{Cl})$ & $\operatorname{NLR}(95 \% \mathrm{Cl})$ & $\operatorname{DOR}(95 \% \mathrm{Cl})$ \\
\hline miR-196a & 0 & 2 & 10 & 20 & $\begin{array}{l}1.00(0.69- \\
1.00)\end{array}$ & $\begin{array}{l}0.60(0.36- \\
0.81)\end{array}$ & $\begin{array}{l}2.24(1.32- \\
3.81)\end{array}$ & $\begin{array}{l}0.14(0.02- \\
0.95)\end{array}$ & $\begin{array}{l}15.89(1.73- \\
145.79)\end{array}$ \\
\hline miR-196b & 0 & 2 & 10 & 20 & $\begin{array}{l}0.90(0.56- \\
1.00)\end{array}$ & $\begin{array}{l}1.00(0.83- \\
1.00)\end{array}$ & $\begin{array}{l}18.26(2.64- \\
126.12)\end{array}$ & $\begin{array}{l}0.21(0.06- \\
0.71)\end{array}$ & $\begin{array}{l}107.46(7.99 \\
1444.70)\end{array}$ \\
\hline miR-196a®196b & 0 & 2 & 10 & 20 & $\begin{array}{l}0.90(0.56- \\
1.00)\end{array}$ & $\begin{array}{l}1.00(0.83- \\
1.00)\end{array}$ & $\begin{array}{l}18.26(2.64- \\
126.12)\end{array}$ & $\begin{array}{l}0.21(0.06- \\
0.71)\end{array}$ & $\begin{array}{l}107.46(7.99 \\
1444.70)\end{array}$ \\
\hline miR-1290 & I & 5 & 30 & 198 & $\begin{array}{l}0.83(0.65- \\
0.94)\end{array}$ & $\begin{array}{l}0.78(0.71- \\
0.83)\end{array}$ & $\begin{array}{l}3.45(2.39- \\
4.99)\end{array}$ & $\begin{array}{l}0.22(0.10- \\
0.49)\end{array}$ & $\begin{array}{l}18.21(6.31- \\
52.56)\end{array}$ \\
\hline miR-191 & I-Ila & 1 & 9 & 22 & 0.67 & 0.84 & 4.22 & 0.40 & 10.67 \\
\hline miR-21 & I-Ila & 1 & 9 & 22 & 0.67 & 0.81 & 3.51 & 0.41 & 8.54 \\
\hline miR-451a & I-Ila & 1 & 9 & 22 & 0.67 & 0.86 & 4.66 & 0.39 & 12.00 \\
\hline $\begin{array}{l}\text { miR-145®150® } \\
223 \llbracket 636\end{array}$ & I-Ila & 9 & 420 & 2082 & $\begin{array}{l}0.77(0.73- \\
0.81)\end{array}$ & $\begin{array}{l}0.64(0.62- \\
0.66)\end{array}$ & $\begin{array}{l}1.83(1.54- \\
2.18)\end{array}$ & $\begin{array}{l}0.40(0.33- \\
0.48)\end{array}$ & $\begin{array}{l}4.65(3.26- \\
6.64)\end{array}$ \\
\hline $\begin{array}{l}\mathrm{miR}-26 \mathrm{~b} \otimes 34 \mathrm{a} \square \\
122 \rrbracket 126 \rrbracket 145 \rrbracket \\
150 \rrbracket 223 \rrbracket 505 \rrbracket \\
636 \rrbracket 885-5 \mathrm{p}\end{array}$ & I-Ila & 9 & 420 & 2082 & $\begin{array}{l}0.80(0.76- \\
0.84)\end{array}$ & $\begin{array}{l}0.80(0.79- \\
0.82)\end{array}$ & $\begin{array}{l}3.23(2.55- \\
4.09)\end{array}$ & $\begin{array}{l}0.33(0.23- \\
0.48)\end{array}$ & $\begin{array}{l}10.20(6.03- \\
17.26)\end{array}$ \\
\hline Overall & 0 -Ila & 32 & 927 & 4488 & $\begin{array}{l}0.79(0.76- \\
0.82)\end{array}$ & $\begin{array}{l}0.74(0.68- \\
0.79)\end{array}$ & $\begin{array}{l}2.60(2.19- \\
3.10)\end{array}$ & $\begin{array}{l}0.35(0.30- \\
0.41)\end{array}$ & $\begin{array}{l}8.14(5.85- \\
11.33)\end{array}$ \\
\hline
\end{tabular}

\subsection{The diagnostic performance of conventional biomarkers}

Besides circulating miRNAs, some researchers have also evaluated the diagnostic efficacy of conventional biomarkers, such as CA19-9, CEA, and CA242.

Among these conventional biomarkers, CA19-9 was the most frequently studied. The SEN, SPE, PLR, NLR, DOR, and AUC of CA19-9 in discriminating PC from non-PC were 0.78 (0.75-0.80), 0.90 (0.85-0.94), 7.90 (5.14-12.13), 0.25 (0.22-0.28), 31.89 (18.96-53.62), and 0.85 (0.82-0.88), respectively. The sensitivity of CEA and CA242 was similar to that of CA19-9, but the specificity is significantly lower than that of CA19-9. CEA distinguished PC from non-PC with a SEN and SPE of $0.79(0.39-0.96)$ and $0.32(0.08-0.72)$, respectively. The PLR, NLR, DOR and AUC of CEA were 1.17 (0.82-1.65), 0.65 (0.26-1.60), $1.80(0.55-5.88)$ and 0.59 (0.54-0.63), respectively. The SEN, SPE, PLR, NLR, DOR, and AUC of CA242 were 0.79 (0.52-0.93), 0.46 (0.21-0.74), $1.47(0.95-2.27), 0.45(0.21-0.97), 3.25$ (1.14-9.32) and 0.68 (0.63-0.71), respectively. The results were listed in Fig. 2 (E) and Table 2.

\subsection{The diagnostic performance of circulating miRNAs combined with CA19-9}

The combination of circulating miRNAs and CA19-9 for the diagnosis of PC exhibited a significantly higher diagnostic accuracy than that of using of circulating miRNAs or CA19-9 alone. The SEN, SPE, PLR, NLR, DOR, AUC of miRNAs combined CA19-9 in differentiating PC from nonPC were 0.84 (0.80-0.87), 0.84 (0.80-0.87), 9.77 (7.65-12.47), 0.17 (0.14-0.22), 56.01 (37.70-83.20) and 0.94 (0.92-0.96), respectively. The results were listed in Fig. $2(\mathrm{~F}-\mathrm{H})$ and Table 2.

The combination of miR-196, 200 and CA19-9 exhibited a high SEN of more than $90 \%$. Combinations with a SPE greater than $90 \%$ including the combination of miR-1290, CA19-9, the combination of miR-16, CA19-9, the combination of miR-16, 196a, CA19-9, the combination of miR-145, $150,223,636$, CA19-9, the combination of 26b, 34a, 122, 126, 145, 150, 223, 505, 636, 885-5p, CA19-9. There are 4 combinations with SEN and SPE exceeding $90 \%$. They are the combination of miR-210, CA19-9, the combination of miR-25 and CA19-9, the combination of miR-196a, 210 , CA19-9, the combination of 181a, 181b, 210, CA19-9. The results were listed in Table S3.

\subsection{Subgroup analysis and threshold effect analysis}

Since significant heterogeneity presented in our meta-analysis $\left(1^{2}>50 \%\right)$, random-effects model was applied for pooled analysis. Meanwhile, subgroup analysis of five potential sources of heterogeneity including region, conference test, miRNAs profiling, non-PC controls population and specimen, was conducted to identify the source of heterogeneity. However, the results suggested that the $I^{2}$ value of most subgroups was still greater than $50 \%$, indicating that these factors were not associated with heterogeneity. The results were listed in Table S4.

Page $11 / 16$ 
The value of the spearman correlation coefficient was $-0.276(p=0.000)$ in the threshold effect analysis, suggesting the existence of a threshold effect, which may be the main source of heterogeneity in the present meta-analysis.

\subsection{Sensitivity analysis and publication bias}

A sensitivity analysis was performed to validate the reliability of our results. Any removal of the original studies did not have a significant impact on the results and corresponding $95 \% \mathrm{Cl}$, suggesting that the results were stable. Deeks' funnel plots provided no evidence for publication bias $(P>0.05)$.

\section{Discussion}

Although the incidence of PC is not high compared with that of other cancers, it is indeed one of the most lethal cancers because of its high invasiveness and rapid progression[59]. It is difficult to diagnose early-stage PC due to the lack of specific clinical manifestations of patients and auxiliary examination modalities with high sensitivity and specificity. Approximately $50-60 \%$ of patients have had distant metastases when they are diagnosed with PC[60], which leads to a relatively low five-year survival rate of about less than $3 \%$ since the prognosis is closely correlated with the stage at the time of diagnosis[61]. CA19-9 is a tumor antigen that was first discovered in 1979. It has been serving as a PC biomarker for decades[59]. However. A meta-analysis of 19 included studies showed the insufficient diagnostic accuracy of CA19-9 with a pooled SEN and SPE of $0.78(0.75-0.81)$ and 0.73 (0.69-0.76), respectively[62]. Moreover, CA19-9 will also exhibit false-positive results in some non-PC cancers (gastric cancer, ovarian cancer, etc.) and even some benign disorders[63]. Based on such clinical setting, liquid biopsy has been very popular in recent years, since it may complement conventional diagnostic methods. The rationale of liquid biopsy is that tumors can release various forms of substances into body fluids, which provide an opportunity for us to detect tumors[64]. Circulating miRNAs is one of the biomarkers in liquid biopsies and many diagnostic studies on circulating miRNAs have been published each year.

In the present meta-analysis, we found that the SEN, SPE, and AUC of circulating single miRNAs in discriminating PC from non-PC were 0.78 (0.76-0.81), $0.78(0.75-0.80)$, and $0.85(0.82-0.88)$, respectively. The diagnostic performance of the miRNAs panel was not significantly improved compared with single miRNAs. The SEN, SPE, and AUC were 0.79 (0.76-0.82), $0.75(0.72-0.78)$, and 0.84 (0.80-0.87), respectively. Overall, the pooled SEN, SPE, and AUC of circulating miRNAs (including single miRNAs and miRNAs panel) were 0.79 (0.77-0.81), 0.77 (0.75$0.79)$, and $0.85(0.81-0.87)$, respectively. In addition, we also summarized the data of CA19-9 in the included studies and found that the SEN, SPE, and AUC of CA19-9 in distinguishing between PC and non-PC were 0.78 (0.75-0.80), 0.90 (0.85-0.94) and 0.85 (0.82-0.88), respectively. AUC is an indicator that comprehensively reflects the diagnostic efficacy of a biomarker. It is generally considered that an AUC of $0.8-0.9$ indicates that diagnostic efficacy is acceptable. An AUC above 0.9 represents a high diagnostic potency[65]. The AUC of both circulating miRNAs and CA19-9 were above 0.8 , suggesting that the diagnostic efficacy of them was acceptable. An inspiring finding of the present metaanalysis was that the combination of miRNAs and CA19-9 greatly improved the diagnostic accuracy. The pooled SEN, SPE, and AUC of the combination were $0.84(0.80-0.87), 0.91(0.89-0.93)$ and $0.94(0.92-0.96)$, respectively. Therefore, we concluded that the combination of circulating miRNAs and CA19-9 may be a novel and better strategy for the diagnosis of PC. In addition to the pooled analysis, we also summarized the diagnostic accuracy of all the single miRNAs, miRNAs panels and the combinations of miRNAs and CA19-9 involved in the included studies. Some miRNAs and combinations exhibited excellent diagnostic performance. For these miRNAs or combinations, their diagnostic efficacy can be further verified, and even their association with the development, progression, and prognosis of PC may also be a valuable topic.

Early diagnosis of PC has been a problem for a long time. In our meta-analysis, we found that circulating miRNAs also exhibited satisfactory diagnostic efficacy in early-stage PC patients, which was defined as PC patients with a TNM stage of 0-Ila. The AUC was 0.81 (0.77-0.84), and the SEN and SPE were $0.79(0.76-0.82)$ and $0.74(0.68-0.79)$, respectively. MiR-196b and the combination of miR-196a and 196b exhibited high diagnostic accuracy with a SEN and SPE both greater than $90 \%$.

Heterogeneity, which is a common situation in the diagnostic meta-analysis, is the result of variations between different included studies[66]. These variations mainly include differences in the study population, study design, interventions and the interpretation of results. In general, heterogeneity is derived from the threshold effect and non-threshold effect. Since heterogeneity has existed in the present meta-analysis, we first performed a threshold effect analysis, in which the Spearman correlation coefficient was $-0.276(p=0.000)$, indicating the existence of a threshold effect. In addition, we further explored heterogeneous sources of non-threshold effects through subgroup analysis. Based on available data, we mainly explored the region, conference test, miRNAs profiling, non-PC controls population and specimen. Regretfully, the results of the subgroup analysis negated the hypothesis that heterogeneity was caused by these five factors. In summary, we considered that heterogeneity may be derived from the following aspects: (1) Threshold effect. Different circulating miRNAs were involved in included studies. More importantly, the diagnostic cut-off values also varied, leading to heterogeneity to some extent; (2) Normalization controls varied among studies. Currently, there is no consensus on the selection of normalization controls when performing PCR quantification of miRNAs; (3) Most of the included studies were conducted in Asia, which may also introduce bias. 
The advantages of the present meta-analysis are as follows: (1) We have conducted a literature search, study selection, and quality assessment in strict accordance with the PRISMA guideline and included a total of 46 high-quality studies ultimately. The results were more representative;

(2) We have scientifically grouped the original data according to clinical applicability, thus, the results were more instructive for clinical work; (3) In addition to the pooled analysis, we have also accomplished a detailed summary. The diagnostic accuracy of 58 single miRNAs, 23 miRNAs panels and 18 combinations of miRNAs and CA19-9 was summarized, providing evidence-based support for further clinical applications and basic researches. However, some limitations also exist in the present meta-analysis: (1) Heterogeneity was found in our study, which may affect the reliability of the results to some extent; (2) All the included studies didn't avoid a case-control study design, which is a classic diagnostic study model, but not the best type. According to the statement of the QUADAS-2 group, a high-accuracy diagnostic study should also enroll some "difficult-to-diagnose" patients, otherwise, the diagnostic performance may be overestimated[12]. Subsequent diagnostic study researchers should manage to avoid this issue.

\section{Conclusions}

The results of the present meta-analysis showed that circulating miRNAs yielded a high diagnostic accuracy for PC. More importantly, it also exhibited satisfactory diagnostic performance for early-stage PC, catering to the urgent need for an ideal biomarker for early-stage PC in the clinical settings. The combination of circulating miRNAs and the traditional marker CA19-9 can further improve the diagnostic efficacy, which may be a novel strategy for PC diagnosis. However, its diagnostic efficacy still needs further validation by more high-quality and large-scale diagnostic research.

\section{Abbreviations}

PC:pancreatic cancer; USPSTF:US Preventive Services Task Force; CT:computed tomography; MRI:magnetic resonance imaging; US:ultrasound; CA19-9:carbohydrate antigen 19 - 9; EUS:endoscopic ultrasonography; EUS-FNA:EUS-guided fine-needle aspiration; CTCs:circulating tumor cells; cfDNAs:cell-free circulating tumor DNAs; miRNAs:microRNAs; LncRNAs:Iong non-coding RNAs; TEPs:tumor educated platelets; CNKI:China National Knowledge Infrastructure; QUADAS-2:Quality Assessment of Diagnostic Accuracy Studies 2; TP:true positive; TN:true negative; FP:false positive; FN:false negative; SEN:sensitivity; SPE:specificity; PLR:positive likelihood ratio; NLR:negative likelihood ratio; DOR:diagnostic odds ratio; $\mathrm{Cl}$ :confidence interval; sROC:summary receiver operating characteristics curve; AUC:area under the curve.

\section{Declarations}

\section{Ethics approval and consent to participate}

Not applicable.

\section{Consent for publication}

Not applicable.

\section{Availability of data and material}

Please contact author for data requests.

\section{Competing interests}

Not applicable.

\section{Funding}

National Natural Science Foundation of China (NSFC) (81873589).

\section{Authors' contributions}

PC primarily drafted the article, did the actual writing, and performed the meta-analysis; LZQ extracted the data, assessed the study quality; HLH conducted intensive revision of manuscript; WJL provided essential technical support and assistance for statistical analysis; GWZ and LYF designed the search strategy and performed the searching; LX established the inclusion and exclusion criteria; YX contributed to the concept design, critical revision, and finalization of the manuscript.

\section{Acknowledgements}

Not applicable. 


\section{References}

1. Bray F, J Ferlay, I Soerjomataram, R L Siegel, L A Torre, and A Jemal, Global cancer statistics 2018: GLOBOCAN estimates of incidence and mortality worldwide for 36 cancers in 185 countries [J]. CA Cancer J Clin, 2018. 68(6): 394-424.

2. Owens D K, K W Davidson, A H Krist, M J Barry, M Cabana, A B Caughey, et al., Screening for Pancreatic Cancer: US Preventive Services Task Force Reaffirmation Recommendation Statement [J]. Jama, 2019. 322(5): 438-444.

3. Lu C, C F Xu, X Y Wan, H T Zhu, C H Yu, and Y M Li, Screening for pancreatic cancer in familial high-risk individuals: A systematic review [J]. World J Gastroenterol, 2015. 21(28): 8678-8686.

4. National Cancer Institute ( $\mathrm{NCl})$. Cancer Stat Facts: pancreatic cancer. NCl website. https://seer.cancer.gov/statfacts/html/pancreas. html. Assessed June 12, 2019.

5. Moutinho-Ribeiro P, G Macedo, and S A Melo, Pancreatic Cancer Diagnosis and Management: Has the Time Come to Prick the Bubble? [J]. Front Endocrinol (Lausanne), 2018. 9: 779.

6. Qian L, Q Li, K Baryeh, W Qiu, K Li, J Zhang, et al., Biosensors for early diagnosis of pancreatic cancer: a review [J]. Transl Res, 2019. 213 : 67-89.

7. Berry W, J Lundy, D Croagh, and B J Jenkins, Reviewing the Utility of EUS FNA to Advance Precision Medicine in Pancreatic Cancer [J]. Cancers (Basel), 2018. 10(2).

8. Kandel P and M B Wallace, Advanced EUS Guided Tissue Acquisition Methods for Pancreatic Cancer [J]. Cancers (Basel), 2018. 10(2).

9. Buscail E, C Maulat, F Muscari, L Chiche, P Cordelier, S Dabernat, et al., Liquid Biopsy Approach for Pancreatic Ductal Adenocarcinoma [J]. Cancers (Basel), 2019. 11(6).

10. Bracken C P, H S Scott, and G J Goodall, A network-biology perspective of microRNA function and dysfunction in cancer [J]. Nat Rev Genet, 2016. 17(12): 719-732.

11. Moher D, A Liberati, J Tetzlaff, and D G Altman, Preferred reporting items for systematic reviews and meta-analyses: the PRISMA statement [J]. PLoS Med, 2009. 6(7): e1000097.

12. Whiting P F, A W Rutjes, M E Westwood, S Mallett, J J Deeks, J B Reitsma, et al., QUADAS-2: a revised tool for the quality assessment of diagnostic accuracy studies [J]. Ann Intern Med, 2011. 155(8): 529-536.

13. Akamatsu M, N Makino, Y Ikeda, A Matsuda, M Ito, Y Kakizaki, et al., Specific MAPK-Associated MicroRNAs in Serum Differentiate Pancreatic Cancer from Autoimmune Pancreatitis [J]. PLoS One, 2016. 11(7): e0158669.

14. Cao Z, C Liu, J Xu, L You, C Wang, W Lou, et al., Plasma microRNA panels to diagnose pancreatic cancer: Results from a multicenter study [J]. Oncotarget, 2016. 7(27): 41575-41583.

15. Chen Q, L Yang, Y Xiao, J Zhu, and Z Li, Circulating microRNA-182 in plasma and its potential diagnostic and prognostic value for pancreatic cancer [J]. Med Oncol, 2014. 31(11): 225.

16. Deng T, Y Yuan, C Zhang, C Zhang, W Yao, C Wang, et al., Identification of Circulating MiR-25 as a Potential Biomarker for Pancreatic Cancer Diagnosis [J]. Cell Physiol Biochem, 2016. 39(5): 1716-1722.

17. Gao L, S B He, and D C Li, Effects of miR-16 plus CA19-9 detections on pancreatic cancer diagnostic performance [J]. Clin Lab, 2014. 60(1): 73-77.

18. Goto T, M Fujiya, H Konishi, J Sasajima, S Fujibayashi, A Hayashi, et al., An elevated expression of serum exosomal microRNA-191, - 21, -451a of pancreatic neoplasm is considered to be efficient diagnostic marker [J]. BMC Cancer, 2018. 18(1): 116.

19. Hua Y, H Chen, L Wang, F Wang, P Wang, Z Ning, et al., Low serum miR-373 predicts poor prognosis in patients with pancreatic cancer [J]. Cancer Biomark, 2017. 20(1): 95-100.

20. Huang Z, W Chen, Y Du, Q Guo, Y Mao, X Zhou, et al., Serum miR-16 as a potential biomarker for human cancer diagnosis: results from a large-scale population [J]. J Cancer Res Clin Oncol, 2019. 145(3): 787-796.

21. Kawaguchi T, S Komatsu, D Ichikawa, R Morimura, M Tsujiura, H Konishi, et al., Clinical impact of circulating miR-221 in plasma of patients with pancreatic cancer [J]. Br J Cancer, 2013. 108(2): 361-369.

22. Komatsu S, D Ichikawa, M Miyamae, T Kawaguchi, R Morimura, S Hirajima, et al., Malignant potential in pancreatic neoplasm; new insights provided by circulating miR-223 in plasma [J]. Expert Opin Biol Ther, 2015. 15(6): 773-785.

23. Lai X, M Wang, S D McElyea, S Sherman, M House, and M Korc, A microRNA signature in circulating exosomes is superior to exosomal glypican-1 levels for diagnosing pancreatic cancer [J]. Cancer Lett, 2017. 393: 86-93.

24. Lin M S, W C Chen, J X Huang, H J Gao, and H H Sheng, Aberrant expression of microRNAs in serum may identify individuals with pancreatic cancer [J]. Int J Clin Exp Med, 2014. 7(12): 5226-5234.

25. Liu J, J Gao, Y Du, Z Li, Y Ren, J Gu, et al., Combination of plasma microRNAs with serum CA19-9 for early detection of pancreatic cancer [J]. Int J Cancer, 2012. 131(3): 683-691. 
26. Liu R, X Chen, Y Du, W Yao, L Shen, C Wang, et al., Serum microRNA expression profile as a biomarker in the diagnosis and prognosis of pancreatic cancer [J]. Clin Chem, 2012. 58(3): 610-618.

27. Miyamae M, S Komatsu, D Ichikawa, T Kawaguchi, S Hirajima, W Okajima, et al., Plasma microRNA profiles: identification of miR-744 as a novel diagnostic and prognostic biomarker in pancreatic cancer [J]. Br J Cancer, 2015. 113(10): 1467-1476.

28. Qu K, X Zhang, T Lin, T Liu, Z Wang, S Liu, et al., Circulating miRNA-21-5p as a diagnostic biomarker for pancreatic cancer: evidence from comprehensive miRNA expression profiling analysis and clinical validation [J]. Sci Rep, 2017. 7(1): 1692.

29. Que R, G Ding, J Chen, and L Cao, Analysis of serum exosomal microRNAs and clinicopathologic features of patients with pancreatic adenocarcinoma [J]. World J Surg Oncol, 2013. 11: 219.

30. Suzuki R, H Asama, Y Waragai, T Takagi, T Hikichi, M Sugimoto, et al., Fibrosis-related miRNAs as serum biomarkers for pancreatic ductal adenocarcinoma [J]. Oncotarget, 2018. 9(4): 4451-4460.

31. Wang W S, L X Liu, G P Li, Y Chen, C Y Li, D Y Jin, et al., Combined serum CA19-9 and miR-27a-3p in peripheral blood mononuclear cells to diagnose pancreatic cancer [J]. Cancer Prev Res (Phila), 2013. 6(4): 331-338.

32. Zhang J, C Y Zhao, S H Zhang, D H Yu, Y Chen, Q H Liu, et al., Upregulation of miR-194 contributes to tumor growth and progression in pancreatic ductal adenocarcinoma [J]. Oncol Rep, 2014. 31(3): 1157-1164.

33. Zhao C, J Zhang, S Zhang, D Yu, Y Chen, Q Liu, et al., Diagnostic and biological significance of microRNA-192 in pancreatic ductal adenocarcinoma [J]. Oncol Rep, 2013. 30(1): 276-284.

34. Zhou X, Z Lu, T Wang, Z Huang, W Zhu, and Y Miao, Plasma miRNAs in diagnosis and prognosis of pancreatic cancer: A miRNA expression analysis [J]. Gene, 2018. 673: 181-193.

35. Zou X, J Wei, Z Huang, X Zhou, Z Lu, W Zhu, et al., Identification of a six-miRNA panel in serum benefiting pancreatic cancer diagnosis [J]. Cancer Med, 2019. 8(6): 2810-2822.

36. ARZUGUL A, Y Peng, Y NUERMAIMAITI, and Y Ding, Expression of miR-21 and miR-155 in plasma of patients with pancreatic cancer and its clinical significance [J]. Journal of Clinical and Experimental Medicine, 2018. 17(13): 1375-1378.

37. Hu Y, H Zhang, W Shi, W Deng, W Liu, J Tang, et al., Early diagnostic value of plasma miR-155, miR-196a, miR-21 and miR-210 in patients with pancreatic cancer [J]. Tumor, 2015. 35(10): 1135-1143.

38. Hu Y, H Zhang, W Shi, and J Tang, Diagnostic value of plasma miR-210 combined with serum tumor markers in pancreatic cancer [J]. World Chinese Journal of Digestology, 2015. 23(01): 147-152.

39. Liu J, J Gao, Y Du, Z Li, Y Ren, X Wang, et al., Diagnostic value of combined detection of plasma microRNA in pancreatic cancer [J]. Chinese Journal of Digestion, 2011. 31(11): 777-779.

40. Liu J, J Gao, Z Li, Y Ren, X Wang, W Wang, et al., Diagnostic value of plasma miR-155 for pancreatic cancer [J]. Chinese Journal of Pancreatology, 2011. 11(2): 79-81.

41. Liu J, J Gao, Y Ren, X Wang, W Wang, and H Lu, Diagnostic value of plasma miR-21 in pancreatic cancer [J]. World Chinese Journal of Digestology, 2011. 19(08): 860-863.

42. Pan F, Y Wen, S Ma, W Cao, J Dong, Y Zhao, et al., Correlation of serum microRNA profiling with pancreatic cancer risk [J]. ACTA UNIVERSITATIS MEDICINALIS NANJING (Natural Science), 2012. 32(11): 1541-1544.

43. Pan W, A study of plasma miRNA associated with pancreatic cancer diagnosis. 2014, Shandong University.

44. Shi W, Research of abnormal expression of miR-155, miR-196a in the early diagnosis of pancreatic cancer. 2014, Kunming Medical University.

45. Wang S, J Liu, K Lei, and Y Jia, Aberrant overexpressions of microRNAs in plasma and their correlations with the clinical features of patients with pancreatic cancer [J]. Tumor, 2015. 35(08): 905-910.

46. Wang X, Z Tong, and G Jin, Value of serum miR-155 in the diagnosis and prognosis of pancreatic cancer [J]. Chinese Journal of Hepatobiliary Surgery, 2015. 21(3): 189-193.

47. Johansen J S, D Calatayud, V Albieri, N A Schultz, C Dehlendorff, J Werner, et al., The potential diagnostic value of serum microRNA signature in patients with pancreatic cancer [J]. Int J Cancer, 2016. 139(10): 2312-2324.

48. Madhavan B, S Yue, U Galli, S Rana, W Gross, M Muller, et al., Combined evaluation of a panel of protein and miRNA serum-exosome biomarkers for pancreatic cancer diagnosis increases sensitivity and specificity [J]. Int J Cancer, 2015. 136(11): 2616-2627.

49. Schultz N A, C Dehlendorff, B V Jensen, J K Bjerregaard, K R Nielsen, S E Bojesen, et al., MicroRNA biomarkers in whole blood for detection of pancreatic cancer [J]. Jama, 2014. 311(4): 392-404.

50. Skrha P, A Horinek, E Pazourkova, J Hajer, P Fric, J Skrha, et al., Serum microRNA-196 and microRNA-200 in pancreatic ductal adenocarcinoma of patients with diabetes mellitus [J]. Pancreatology, 2016. 16(5): 839-843. 
51. Slater E P, K Strauch, S Rospleszcz, A Ramaswamy, I Esposito, G Kloppel, et al., MicroRNA-196a and -196b as Potential Biomarkers for the Early Detection of Familial Pancreatic Cancer [J]. Transl Oncol, 2014. 7(4): 464-471.

52. Tavano F, D Gioffreda, M R Valvano, O Palmieri, M Tardio, T P Latiano, et al., Droplet digital PCR quantification of miR-1290 as a circulating biomarker for pancreatic cancer [J]. Sci Rep, 2018. 8(1): 16389.

53. Cote G A, A J Gore, S D McElyea, L E Heathers, H Xu, S Sherman, et al., A pilot study to develop a diagnostic test for pancreatic ductal adenocarcinoma based on differential expression of select miRNA in plasma and bile [J]. Am J Gastroenterol, 2014. 109(12): 1942-1952.

54. Ganepola G A, J R Rutledge, P Suman, A Yiengpruksawan, and D H Chang, Novel blood-based microRNA biomarker panel for early diagnosis of pancreatic cancer [J]. World J Gastrointest Oncol, 2014. 6(1): 22-33.

55. Li A, J Yu, H Kim, C L Wolfgang, M I Canto, R H Hruban, et al., MicroRNA array analysis finds elevated serum miR-1290 accurately distinguishes patients with low-stage pancreatic cancer from healthy and disease controls [J]. Clin Cancer Res, 2013. 19(13): 3600-3610.

56. Wang J, J Chen, P Chang, A LeBlanc, D Li, J L Abbruzzesse, et al., MicroRNAs in plasma of pancreatic ductal adenocarcinoma patients as novel blood-based biomarkers of disease [J]. Cancer Prev Res (Phila), 2009. 2(9): 807-813.

57. Hussein N A, Z A Kholy, M M Anwar, M A Ahmad, and S M Ahmad, Plasma miR-22-3p, miR-642b-3p and miR-885-5p as diagnostic biomarkers for pancreatic cancer [J]. J Cancer Res Clin Oncol, 2017. 143(1): 83-93.

58. Alemar B, P Izetti, C Gregorio, G S Macedo, M A Castro, A B Osvaldt, et al., miRNA-21 and miRNA-34a Are Potential Minimally Invasive Biomarkers for the Diagnosis of Pancreatic Ductal Adenocarcinoma [J]. Pancreas, 2016. 45(1): 84-92.

59. Jelski W and B Mroczko, Biochemical diagnostics of pancreatic cancer - Present and future [J]. Clin Chim Acta, $2019.498: 47-51$.

60. Kleeff J, M Korc, M Apte, C La Vecchia, C D Johnson, A V Biankin, et al., Pancreatic cancer [J]. Nat Rev Dis Primers, $2016.2: 16022$.

61. Siegel R L, K D Miller, and A Jemal, Cancer statistics, 2018 [J]. CA Cancer J Clin, 2018. 68(1): 7-30.

62. Meng Q, S Shi, C Liang, D Liang, W Xu, S Ji, et al., Diagnostic and prognostic value of carcinoembryonic antigen in pancreatic cancer: a systematic review and meta-analysis [J]. Onco Targets Ther, 2017. 10: 4591-4598.

63. Parra J L, S Kaplan, and J S Barkin, Elevated CA 19-9 caused by Hashimoto's thyroiditis: review of the benign causes of increased CA 19-9 level [J]. Dig Dis Sci, 2005. 50(4): 694-695.

64. Samandari M, M G Julia, A Rice, A Chronopoulos, and A E Del Rio Hernandez, Liquid biopsies for management of pancreatic cancer [J]. Transl Res, 2018. 201: 98-127.

65. Walter S D, Properties of the summary receiver operating characteristic (SROC) curve for diagnostic test data [J]. Stat Med, 2002. 21(9): 1237-1256.

66. Lijmer J G, P M Bossuyt, and S H Heisterkamp, Exploring sources of heterogeneity in systematic reviews of diagnostic tests [J]. Stat Med, 2002. 21(11): 1525-1537. 